\title{
An Integrated Simulation Optimisation Decision Support Tool for Multi-Product Production Systems
}

\author{
Samira Alvandi ${ }^{1}$, Wen $\mathrm{Li}^{1}$ \& Sami Kara ${ }^{1}$ \\ 1 Sustainable Manufacturing and Life Cycle Engineering Research Group, School of Mechanical and \\ Manufacturing Engineering, University of New South Wales, Sydney, Australia \\ Correspondence: Sami Kara, School of Mechanical and Manufacturing Engineering, University of New South \\ Wales, Sydney, NSW 2052, Australia. Tel: 61-2-9385-5757. E-mail: s.kara@unsw.edu.au
}

Received: November 21, 2016

Accepted:November 30, $2016 \quad$ Online Published: April 23, 2017

doi:10.5539/mas.v11n6p 56

URL: https://doi.org/10.5539/mas.v11n6p56

\begin{abstract}
Over the past decades, the rising energy prices and imposing environmental regulations have motivated manufacturers to improve the energy efficiency of their manufacturing processes. Manufacturers need to also consider energy efficiency in addition to classical performance measures. The additional performance dimension (energy-related indicators) significantly increases the complexity of classical production planning problems (e.g. scheduling), already known as NP-hard problem). To overcome the inherited complexity, an integrated simulation-optimization framework is proposed. The proposed approach tackles scheduling problem in a multi-product/multi-machine manufacturing environment and optimizes several production objectives simultaneously. A case study is presented to demonstrate the applicability of the proposed approach in a real-life industrial facility.
\end{abstract}

Keywords: Energy efficiency, Simulation-Optimisation, Optimal Production Planning, Production Systems

\section{Introduction}

In a typical manufacturing system, time dependencies and dynamics related to multiple product flows affect the material flow (Duggan, 2012) and also the energy consumption (Alvandi et al., 2016). These variables may be associated with a single machine tool or a process chain, or even the whole factory (Herrmann at al., 2014). In other words, cycle time variations and machine job sharing stemming from multitude product routings, can severely impact on the energy consumption of the entire system.

It has been generally acknowledged that efficiency improvements in a factory can only occur when holistic understanding of energy and resource usages is understood (Alvandi et al., 2016). There exists vast energy reducing opportunities on the system-level that advantageously do not require large capital investment. Operational method such as optimised shop floor scheduling is one examp le of such methods. Implementation of optimised shop floor scheduling is normally less costly and can easily be applied to existing systems (Fang et al., 2011).

Up to now, the focus of shop floor scheduling optimisations has been mainly on traditional performance measures such as optimising lead times or minimising slack times on single machine/ parallel-machines. Within the context of multi-objective scheduling, the consideration of the energy related performance (objectives) within the entire factory has been undermined, hence hinders further research.

The focus of this research is to develop a simulation-optimisation framework for solving multi-objective scheduling problem within multi-product systems including all processes within the process chain. In the following sections, current energy related optimisation studies will be briefly explored. In order to address the gap found within the literature, a simulation-optimisation framework will be presented which will be further applied to a manufacturer of composite brake shoes and disc pads for railway industry.

\section{Background}

Most of manufacturing systems involve complex, dynamic systems which consume energy, water and raw materials. Improving energy efficiency with respect to operational methods in the area of job scheduling has been explored by researches in recent years. 
Mouzon et al. (2007) developed several algorithms and a multi-objective mathematical programming model to investigate the problem of scheduling jobs on a CNC machine for reducing energy consumption and total completion time. They pointed out that there was a significant amount of energy savings (up to 80\%) when non-bottleneck machines were turned off and set on idle mode. This research was performed on the machine level and only considers a single machine environ ment and tackled single objective problem; in further work by (Mouzon \& Yildirim, 2008) a multi-objective optimization schedule that minimized the total energy consumption and the total tardiness of one machine was solved.

Fang et al. (2011) presented a multi-objective mixed integer linear programming formulation for optimizing the operating schedule of a flow shop. They considered maximis ing productivity (make span) and minimising energy related (energy consumption, carbon footprint and peak power load). The presented multi-objective model considered a simple case of scheduling 36 jobs on two machines. A Pareto frontier was established that showed the trade-off between throughput time and peak power. An optimal scheduling procedure for sequencing jobs on one process (painting process) has been proposed by (Wang et al., 2009) with the aim to reduce energy consumption in an automotive paint shop.

In order to investigate potential opportunities for energy efficiency and making trade-offs that are transparent to the decision makers, simu lation is a proven modelling technique (Alvandi et al., 2015). In line with the presented body of knowledge, some authors adopted energy oriented discrete event simulation model (Herrmann et al., 2011). The model represented the production system with all the interdependencies and dynamics of technical building services and also considered the technical, economic, and ecological evaluation of the performance of process chains. Melouk et al. (2013) developed simulation optimization-based decision support tool for steel manufacturing and conducted tests on the impact of simultaneous change of inventory levels of both slabs and coils. Within their work, they solved single objective optimisation problem of minimising inventory cost of slabs and coils.

Mousavi et al. (2015) proposed a simulation-optimisation framework to model dynamics of individual processes and the entire system. The method has been applied to a mass production system producing small variety of products with large quantity. Their work evaluated the effects of process parameters and the role of lot-sizing problems while exploring the benefits of simulation techniques for modelling the dynamic energy consumption on a system-level. However, the method falls short when it comes to multi-product/multi-machine environ ments and optimisation of the entire system.

In order to capture the inherited complexity in terms of various product routing and machine job sharing, a modelling framework that considers product level parameters together with machine level and system level is deemed necessary.

\section{Proposed Simulation Optimisation Framework}

Base on (Fu et al., 2000), a general description of the proposed framework for a simulation-optimisation is presented in Figure 1 which is composed of two segments: Simulation model is the first segment and the second segment is an optimisation engine (optimiser) which interacts with the simulation model with its exploratory algorithm.

The simulation and optimisation communicate closely with each other. Firstly, optimisation engine provides trial solutions to the simulation model. Simulation model then runs those solutions and returns the values of objective function to the optimisation engine. Optimisation engine takes advantage of these output results to improve its search for selecting new trial solutions.

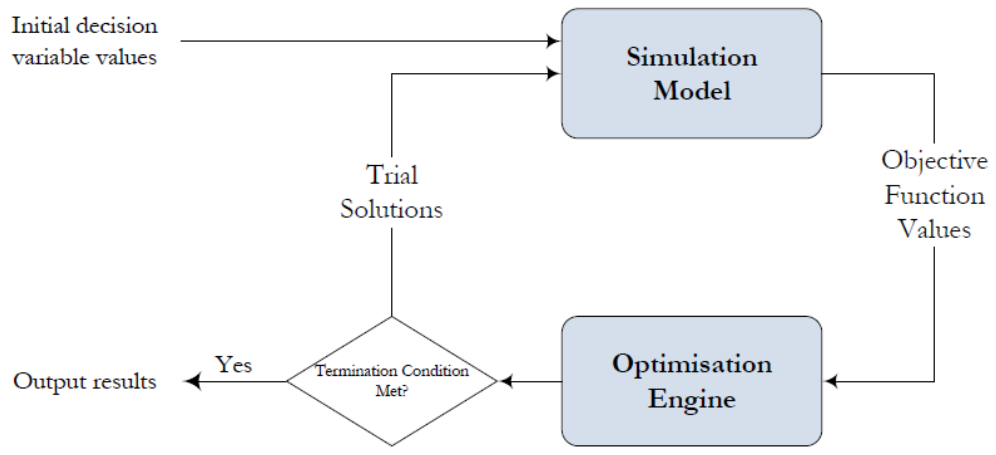

Figure 1. General simulation optimisation framework 


\subsection{Simulation Model}

The simulation model represents the manufacturing system comprising all the process machines, technical building services and process chains with various products flowing in between. A Discrete Event Simulation (DES) model is developed using in the AnyLogic $\AA$ model development environment. As illustrated in Figure 2, the developed simulation model takes a holistic view of the factory and represents the manufacturing system and all the material and energy flows within interactive modules: unit process, process chains and TBS.

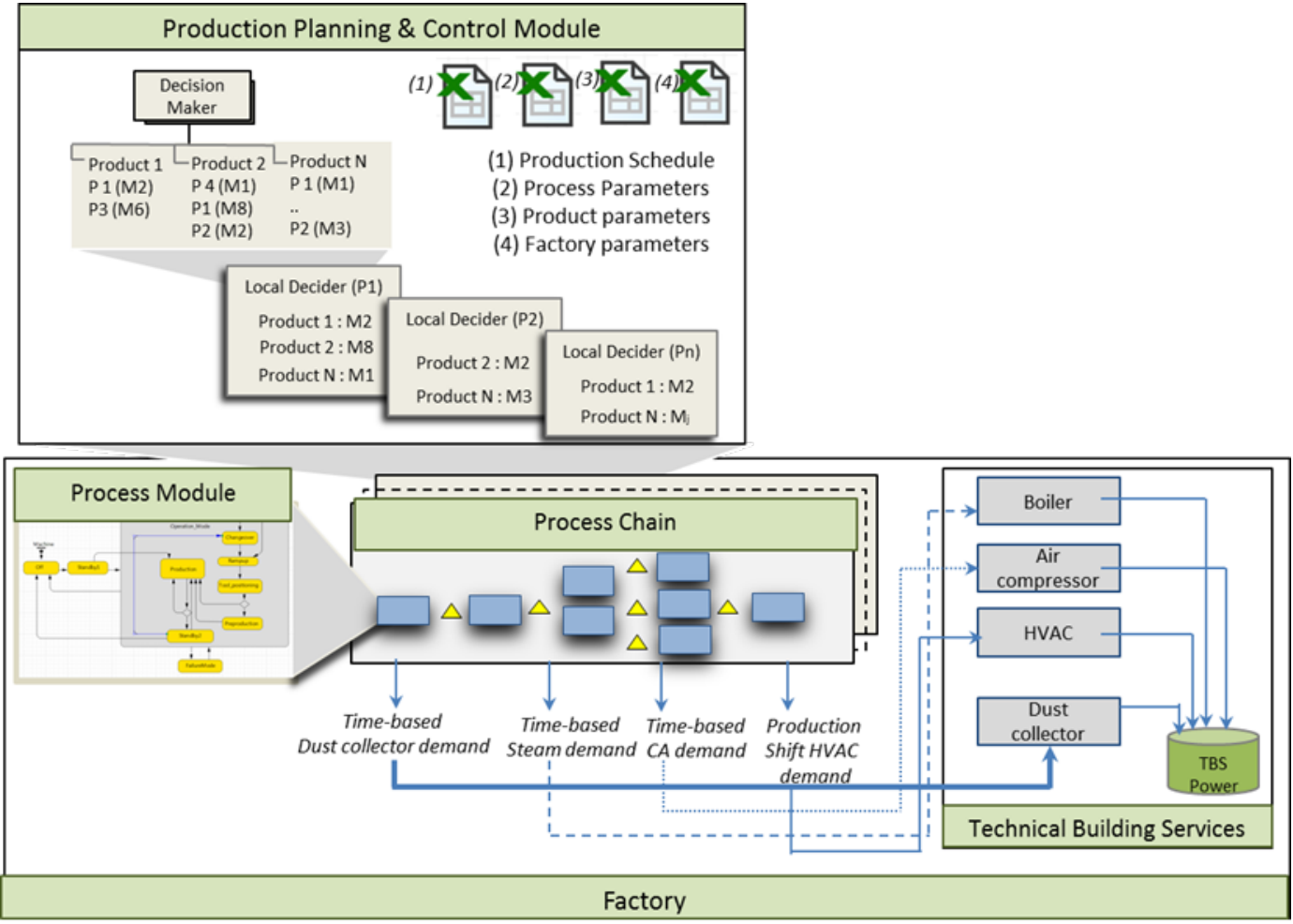

Figure 2. Simulation model framework (adopted from (Herrmann et al., 2011))

Unit Process Module: Each unit process is configured according to the corresponding machine specific parameters (e.g. energy profile, scrap rate, etc.). Basic unit process modules for the representation of machines with different operational states are created by using state charts (Alvandi et al., 2015).Following is a brief explanation on configured machine states:

- Off: refers to the state when the machine is switched off.

- Ramp up: refers to the acceleration of the main drive of the machine when switched on.

- Standby: refers to the period when the machine remains ready for production.

- Preproduction: refers to the activities for preparing the production, such as loading a workpiece.

- Production: refers to the state when the machine is processing the work piece.

- Postproduction: refers to the state when the auxiliary equip ment of the machine (e.g. lubrication pump, chip remover) is activated.

- Changeover: refers to the state when the set-up of the machine is being changed.

- Failure: refers to the state that the machine is broken down and requires maintenance

Process Chain Module: The process chain of a product is defined as responsible processes and machines to transform material to product. Multiple process chains are modelled by linking and connecting the unit processes according to predefined product-machine routing logic. Separate modules are configured to translate the routing matrix for guiding the product passing through multitude of processes and machines (Alvandi et al., 2016).

TBS Module: The process chain requires other resources and auxiliary services such as lighting, heating and compressed air. In the proposed framework, technical building services (TBS) are responsible to supply services such as steam, compressed air, and conditioned air, cooled air and air purification. Similar to unit processes, the TBS models are developed as having different operational states, such as ramp up, standby, production, ramp 
down and off. The supply load on these devices is dependent on the total demand of associated production processes that is configured by the machine specification. Due to high flexibility of AnyLogic ${ }^{\circledR}$, several developed TBS models can be directly connected into the proposed simulation model, such as steam generation units (Ghadimi et al., 2014), compressed air systems and HVAC units the (Mousavi et al., 2014). Figure 2 depicts the proposed framework for the simulation model.

3.2 Optimisation Engine: multi-objective optimisation

There are three main groups of methods for solving multi objective optimisation problem. Methods which consider one objective at a time: the lexicographic method is a good example of methods in this group where all the objective functions are sorted in order of their importance (Marler \& Arora 2004). Other methods such as Weighted Sum method belong to the second group that normalises a set of objectives into a single objective by multiplying each objective with a user defined weight vector (Deb, 2001). The third group considers the objective functions simultaneously and try to find a set of Pareto solutions instead of one single solution.

Weighted Sum is the simplest approach and arguably the most widely used classical approach which is selected for the proposed framework. Weighted Sum solves a multi-objective problem as a single objective. In this method, each sub-objective is solved as a single-objective problem which then will be scaled and weighted depending on its relative importance or weight. The multi-objective function can be maximized or minimize (Equation 1 formulates a minimisation problem).

$$
\begin{array}{lll}
\text { Minimise } & F(X)=\sum_{k m=1}^{n M} W m F m(X) & \\
\text { Subject to } & g_{j}(X) \geq 0, & j=1,2, \ldots, J ; \\
& h_{k}(X)=0, & k=1,2, \ldots, K ; \\
& x i^{(L)} \leq X_{i} \leq x i^{(U)} & i=1,2, \ldots, N ;
\end{array}
$$

where $(\in[0,1])$ is the weight of the m-th objective function so that $\sum_{m=1}^{M} \mathrm{Wm}=1$.

\subsection{Optimisation Engine: Search Method}

Metaheuristic approaches have drawn considerable attention from many researchers in the last decade. Bianchi et al. (2009) identified that these methods are a valid alternative to exact classical optimisation algorithms as well as stochastic comb inatorial optimisation problems. In fact, metaheuristic algorith ms (such as simu lated annealing, Tabu search) have dominated the optimisation routines of simulation software due to their flexibility and robustness $(\mathrm{Fu}, 2002)$.These algorithms are known to be flexible in dealing with any type of solution space (either discrete, continuous or a combination of them) and are capable to quickly achieve high quality solutions.

Advances in the area of metaheuristic optimization coupled with improved computing environments resulted in creation of general-purpose "black box" optimizers (Glover et al., 1999). As a matter of fact, this approach has dominated the optimisation routines of the simulation software o wing to their flexibility in dealing with any type of solution space (either discrete, continuous or a combination of them) and their ability to quickly achieve good quality solutions (Fu, 2002). In black-box approach, the metaheuristic optimizer selects a set of values for the decision variables and uses the responses (or objective function values) generated by the simulation model to make decisions regarding the selection of the next trial solution. This procedure is iterative until a termination condition is fulfilled which means the best solution is found and is returned as the optimal (or near optimal) solution.

OptQuest search engine combines the metaheuristics of Tabu Search, Neural Networks, and Scatter Search into a single search heuristic. A simple way to describe its search mechanism: if a candidate solution does not fit the constraints, OptQuest eliminates that solution and explores candidates that are more likely to be better. The efficiency of OptQuest search algorith $\mathrm{m}$ is very much dependant on the size of the solution space and the starting point (Kleijnen and Wan, 2007).

OptQuest uses three stopping criteria (Kelton \& Law, 2000):

- Run until maximum number of configurations defined by the user is achieved (MNC).

- Run until no improvement is obtained in the value of the objective function for 100 consecutive configurations (Automatic Stop in OptQuest).

- Combination of above rules; optimization runs until non-imp roving configurations are equal to 5 percent of 
MNC.

By using OptQuest ${ }^{\mathrm{TM}}$ to deal with the multi-objective optimization problems, there are a few classical methods that could be applied, like weighted sum approach or goal-oriented optimization as described earlier. Although these approaches are different from each other, their main aim is the same, which is to convert a multi-objective optimization problem into a single-objective optimization problem. A mong these approaches, the weighted sum approach is the simplest and probably the most widely used classical approach. In order to derive theories from practice, the proposed simulation-optimisation methodology was applied to a manufacturer of composite brake shoes and disc pads for the railway industry. Report any other analyses performed, including subgroup analyses and adjusted analyses, indicating those that were pre-specified and those that were exploratory (though not necessarily in the level of detail of primary analyses). Consider putting the detailed results of these analyses on the supplemental online archive. Discuss the implications, if any, of the ancillary analyses for statistical error rates.

4. Case Study

The investigated company offers around 100 different products, which generally are grouped into three product families. These products differ in terms of various material compositions, weight and shape. For the ease of demonstration, six products are chosen- two from each product family. Figure 3 is a representation of the process sequences and a reference map for the flow of 6 product families. In general, all products follow five consecutive processes to be manufactured: weighting, mixing, biscuit pressing, moulding and curing. However, the products vary in shapes, thicknesses, and material compositions to suit different braking systems requirement. As a result, key variables, such as routing and processing time are product specific.

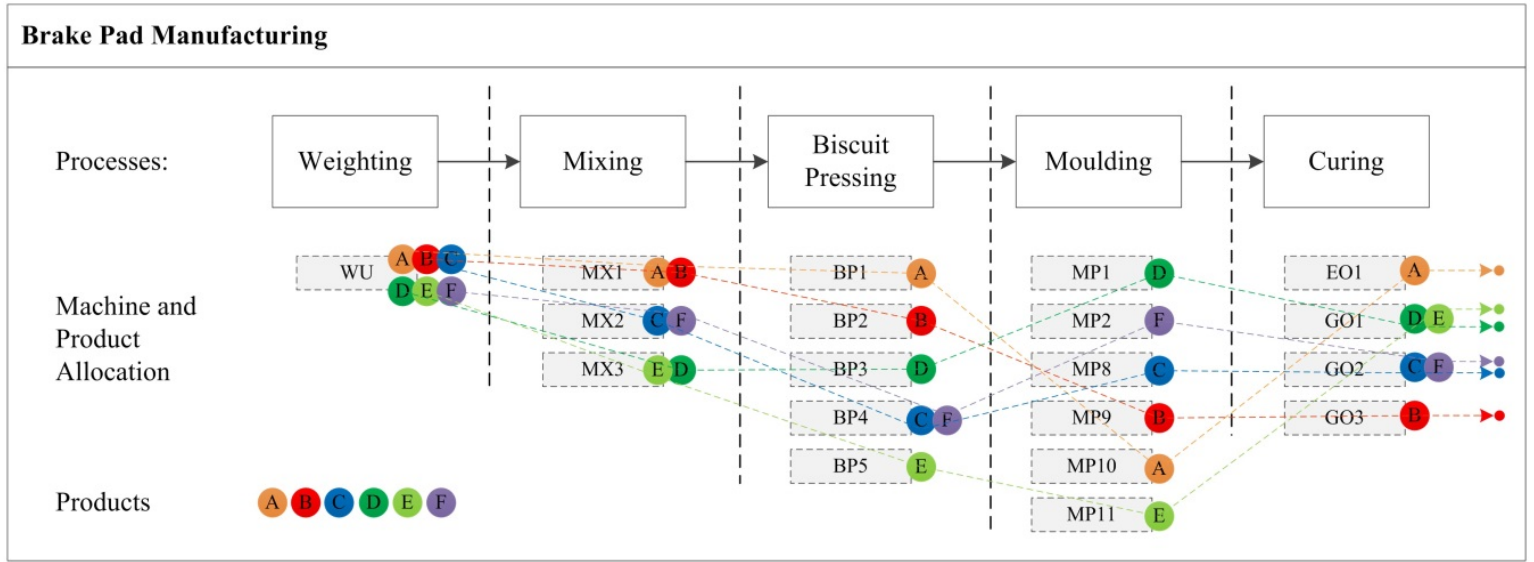

Figure 3. Representation of process sequence and sample product routings(Alvandi et al., 2016)

In the first process step (weighting), there is only one weighting unit (WU) for scaling the raw materials. In mixing, three mixers (MX) are used to generate the friction material compound. The batches of specific products are mixed and stirred until they become a homogeneous mixture. Based on the product (batch) type and the mixer's technical specification (e.g. machine capacity) the batches are assigned to specific mixers.

The mixed compound is transferred to pressing machines where it is pressed into cuboid biscuit shaped units. Depending on the product and material mix, this process step is performed by different biscuit presses (BP). There are five biscuit presses, three automatic and two that are manually operated.

Parallel to the brake pad production line, the back-plates are produced in a separate line. In the moulding workstation, which contains ten moulding presses (MP) and heaters, the biscuits are heated and pressed against their corresponding back-plate to form the actual brake block or pad. Depending on the type of product and material used, either radiofrequency waves or induction is used to heat the biscuits to approximately $150^{\circ} \mathrm{C}$ so they can be moulded in the presses immediately. The presses can be equipped with different types of moulds with different capacity (ranges from two to eight cavities).

Curing is the final process for most of these products, so in this workstation the moulded products are placed into one of five curing ovens including two electric (EO) and three gas ovens (GO). In this process step, depending on the type of product, only one of five programs can be selected. During the curing process, the friction materials are hardened and homogenised. 


\subsection{Data Collection}

The studied organisation utilized Citect v. 7.20 for its SCADA system (supervisory control and data acquisition system) and the Oracle database for enterprise resource planning. The Oracle ${ }^{\circledR}$ ERP system provided useful input information (such as BOM, production schedules) while Citect SCADA ${ }^{\circledR}$ provided detailed machine specific values (such as scrap rate, machine status, mean time between failure (MTBF) and mean time to repair (MTTR)). Table 1 shows an example of model input for configuring the mixing processes.

Table 1. Model input for mixing processes (S. Alvandi et al., 2016)

\begin{tabular}{|c|c|c|c|c|c|c|c|c|c|}
\hline \multirow[b]{2}{*}{ Resources } & \multicolumn{3}{|c|}{ Product specific paramaters } & \multicolumn{6}{|c|}{ Machine specific parameters } \\
\hline & $\begin{array}{l}\text { Product } \\
\text { type }\end{array}$ & $\begin{array}{l}\text { Lot } \\
\text { size } \\
\text { (qty) }\end{array}$ & \begin{tabular}{l}
\multicolumn{2}{l}{ Production } \\
time / lot \\
$(\mathrm{min})$
\end{tabular} & $\begin{array}{l}\text { Setup } \\
\text { time } \\
(\mathrm{min}) \\
\end{array}$ & $\begin{array}{l}\text { Production } \\
\text { power }(\mathrm{kW})\end{array}$ & $\begin{array}{l}\text { Standby } \\
\text { power } \\
(\mathrm{kW})\end{array}$ & $\begin{array}{l}\text { Scrap } \\
\text { rate } \\
(\%) \\
\end{array}$ & $\begin{array}{l}\text { MTTR } \\
(\min )\end{array}$ & $\begin{array}{l}\text { MTBF } \\
\text { (min) }\end{array}$ \\
\hline \multirow{2}{*}{ MX1 } & A & 26 & 21 & \multirow{2}{*}{300} & \multirow{2}{*}{5.56} & \multirow{2}{*}{0.22} & \multirow{2}{*}{1} & \multirow{2}{*}{100} & \multirow{2}{*}{2000} \\
\hline & $\mathrm{B}$ & 222 & 40 & & & & & & \\
\hline \multirow{2}{*}{ MX2 } & $\mathrm{C}$ & 170 & 14 & \multirow{2}{*}{300} & \multirow{2}{*}{22.3} & \multirow{2}{*}{0.12} & \multirow{2}{*}{2} & \multirow{2}{*}{100} & \multirow{2}{*}{2000} \\
\hline & $\mathrm{F}$ & 192 & 33 & & & & & & \\
\hline \multirow{2}{*}{ MX3 } & $\mathrm{D}$ & 143 & 32 & \multirow{2}{*}{300} & \multirow{2}{*}{9.71} & \multirow{2}{*}{0.05} & \multirow{2}{*}{1} & \multirow{2}{*}{100} & \multirow{2}{*}{2000} \\
\hline & $\mathrm{E}$ & 81 & 32 & & & & & & \\
\hline
\end{tabular}

Every product in this system has its own batch size, which means that the batches contain a different number of products. These products are stored in front of the machine according to their types, and when a given storage reaches its batch size; all the stored products are released and assigned to the machine. From a modelling perspective, there are two dynamic parameters in the process module which change depending on the product type, i.e., the batch size and production time, both of which require new value for each process module when a new product is ready for production. After a given product has been processed on a particular machine, the model checks the product routing to determine the relevant machine for the consequent process and then assigns the product to that machine.

\subsection{Data Collection}

Routing dictates the process steps that the product must go through as well as the specific machine tool for that processing step. Table 2 shows the routing and production times of each product family. Routing in the weighing and mixing workstations is not flexible because each product family can be processed on only one machine, unlike the biscuit pressing, moulding and curing workstations where products in the same family have several alternative machines. In the simulated case, the product routing was predetermined by production planner according to product specification and machine technical specification.

Also within Table 2, the established production times are per unit of product. Because the product flows in different forms and units, the production time should be scaled accordingly. In weighting, mixing, and biscuit pressing, the time is per batch since based on the batch size and weights, production times vary. In moulding the time is given per product because the shape of the product changes after raw materials have been pressed into blocks. Finally, production time in the curing workstation is per cycle because processing does not commence until the ovens are full. 
Table 2. Routing and production times of different product families

\begin{tabular}{lllll}
\hline \multirow{2}{*}{ Workstation } & \multirow{2}{*}{ Machine } & \multicolumn{3}{l}{ Product Family } \\
\cline { 3 - 5 } Weighting (Min) & WU1 & 7 & 28 & II \\
\hline \multirow{3}{*}{ Mixing (Min) } & MX1 & - & - & 14 \\
& MX2 & 21 & - & - \\
& MX3 & - & 40 & - \\
\hline \multirow{5}{*}{ Biscuit Pressing (Min) } & BP1 & - & 0.67 & - \\
& BP2 & - & 0.67 & - \\
& BP3 & 3.2 & - & - \\
& BP4 & - & - & 0.7 \\
& BP5 & 3.2 & - & - \\
\hline \multirow{5}{*}{ Moulding (Min) } & MP1 & - & 2.2 & 2.11 \\
& MP2 & - & 2.2 & 2.11 \\
& MP3 & - & 2.2 & 2.11 \\
& MP4 & 3.35 & - & - \\
& MP5 & - & 2.2 & 2.11 \\
& MP6 & 3.35 & - & - \\
& MP7 & - & - & 2.11 \\
& MP8 & - & 2.2 & 2.11 \\
& MP9 & - & 2.2 & 2.11 \\
& MP10 & - & 2.2 & 2.11 \\
\hline \multirow{5}{*}{ Curing (Min) } & EO1 & 14 & - & - \\
& EO2 & 14 & - & - \\
& GO1 & 4 & 10 & 4 \\
& GO2 & 4 & 10 & 4 \\
& GO3 & 4 & 4 & 4 \\
\hline
\end{tabular}

The production system operates on 2-shifts/day for 5-days/week. Production starts at 6 AM and finishes at 10 PM. For the purpose of this study a copy of the (weekly) production plan for one month was obtained from the production planning department and then the system was simulated. With regards to energy consumption, the amount of electricity consumed by each machine during different operational states is measured by a portable power analyser and then determined by studying the energy profile. With regards to the consumption of gas in the ovens, the nameplate values of each machine were used and further validated with the gas meter readings.

4.3 Simulation Validation

A model for the entire factory was developed in Anylogic ${ }^{\circledR}$, Microsoft Excel ${ }^{\circledR}$ and Java ${ }^{\circledR}$ using the method described in Section 3. It involved configuring the production processes in Anylogic ${ }^{\circledR}$ and defining the production parameters in Microsoft Excel ${ }^{\circledR}$. A snapshot of this simulation model is shown in Figure 4.

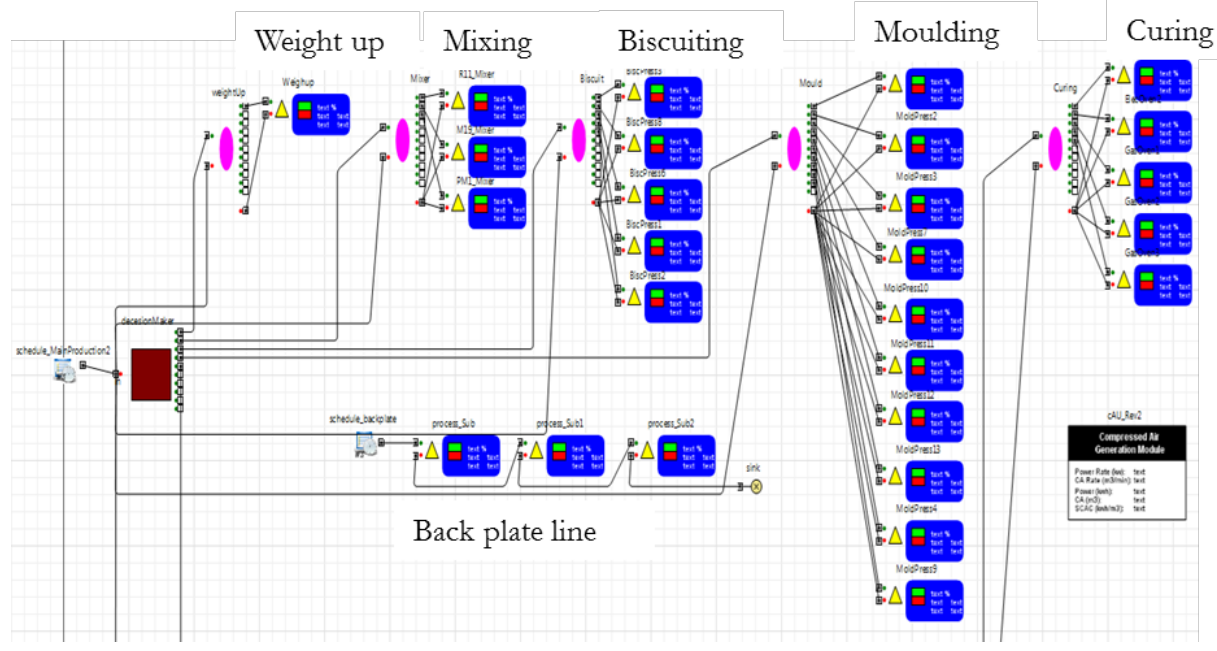

Figure 4. Snapshot of the simulation model 
The daily electricity consumed by the entire factory was simulated for a period of one month, and then compared with the actual consumption data. The simulation run was set to continue for five weeks. One week was dedicated (as transient phase) to warming up the system where the simulation results were disregarded. Having a warm-up period ensured that the simulation was not influenced by the initial conditions and it had reached a steady-state phase before collecting data from the simulation (Banks, 1998). The results of the daily electricity consumption simulation of the entire factory for the given month were compared with actual consumption data and shown in Figure 5.

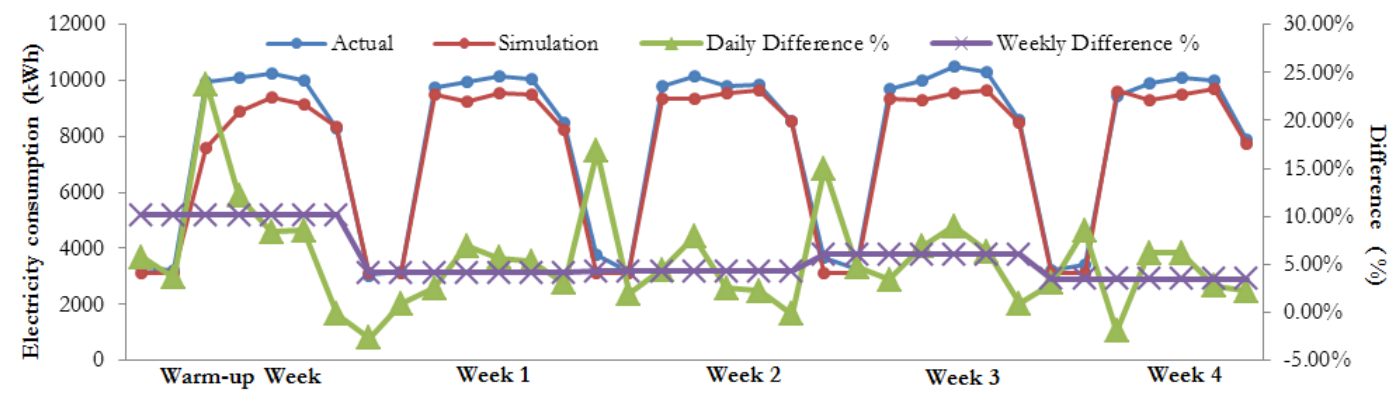

Figure 5. Daily electricity consumption of the entire factory; Actual data vs. Simulation

The simulation error is determined by calculating the ratio of the difference between the simulated and actual total electricity consumption to actual total electricity consumption ( see Equation 2).

$$
\text { Difference } \%=\frac{(\text { Actual }- \text { Simulation })}{\text { Actual }} * 100
$$

As Figure 5suggests, the daily simulation error is less than $10 \%$ on average. Notably, the first three Saturdays as can be seen, cause the highest difference between 14-18\%. A close investigation has identified an unplanned weekend production (over time work to catch up delayed orders) on the curing ovens has been carried out which was not included in the simulation. Furthermore, the model shows a higher accuracy for estimating the energy consumption at an aggragated level (e.g. weekly and monthly). Table 3shows the comparison between the simulated factory energy consumption and the factory energy measurements on weekly and monthly basis.

Table 3. Comparison between actual consumption and simulation

\begin{tabular}{lccc}
\hline Performance indicator & Actual & Simulated & Variance \\
\hline Week 1 Electricity in kWh & 54570.098 & 52318.48288 & $4.13 \%$ \\
\hline Week 2 Electricity in kWh & 55067.195 & 52688.98872 & $4.32 \%$ \\
\hline Week 3 Electricity in kWh & 55995.25 & 52604.48155 & $6.06 \%$ \\
\hline Week 4 Electricity in kWh & 53987.44 & 52088.92735 & $3.52 \%$ \\
\hline Monthly total Electricity in kWh & 219619.983 & 209700.8805 & $4.5 \%$ \\
\hline
\end{tabular}

\subsection{Solving Multi-Objective Optimisation}

In this case study, each product family has several feasible alternative machines for carrying out required operations. Product routing problem in this environment consists of assignment of each operation to a machine. When considerable routing flexibility exists in a production system, changing product routing may significantly affect system's throughput and work-in-process inventory (Calabrese \& Haus man, 1991). On these basis, the main objectives to be considered for this case study are maximis ing product throughput, minimising factory energy consumption while minimising lead time of products. In the following section, the decision variables and objective functions will be discussed in more details.

\section{Model Settings}

As for arranging and setting OptQuest ${ }^{\circledR}$ parameters for the optimisation, new parameters are introduced to the simulation model. These new parameters act as representation of the routing and for configuring those, discrete numbers are selected with defined Min/Max and step size. The Min/Max numbers are reflective of the number of the actual machine under each process. For example the decision variable set up for Product A for presentation 
purposes is shown in Table 4. For the rest of the product types, same optimisation parameter setting is performed but due to space limitation, all tables are not presented.

Table 4. List of decision variables for product A for optimisation

\begin{tabular}{lllll}
\hline Parameter & Type & Min & Max & Step \\
\hline ProductA_mixingMachine & discrete & 1 & 3 & 1 \\
ProductA_biscuitingMachine & discrete & 1 & 5 & 1 \\
ProductA_mouldingMachine & discrete & 9 & 10 & 1 \\
ProductA_curingMachine & discrete & 1 & 5 & 1 \\
\hline
\end{tabular}

The production is simulated for a two week period where the first week is considered as a warm up period thus the system performance related to this period was discarded. Therefore, the objective functions were only measured for the second week. Real-world problems mostly contain computationally expensive objective functions that may result in optimization runs that take several days. Stopping criteria are needed to terminate the execution of optimization algorithms. The automatic stop is chosen as a stopping criterion with in OptQuest which terminates the optimisation when the algorithm determined that new solutions are not likely to produce a better objective value.

\section{Decision Variables}

The aim is to find the best choice of machines under each process step (Mixing, Biscuit pressing, Moulding, and Curing) for ten products. This study only focuses on finding the best routing for the ten selected products, representing all three product families. For selecting the ten products, the production order book for a particular month was studied. The order quantities for each product were ranked and the result showed that 10 of the products were responsible for $90 \%$ of production load.

The choice of machines to be used for each process for a particular product follows a set of heuristic rules which considers technical capability of the machine for processing a particular product. Some of the heuristic rules in assigning the product type to the machine include all mixers and all biscuit pressing machines, because there is no limitation in terms of technical compatibility between the machines and the products. Nevertheless, utilisation of moulding machines on product types has limits. From technical point of view, product in group I (as shown in Table 2) can only be processed on MP9 and MP10 whereas the rest of the products can go to any mould machines. Also not all curing ovens are suitable for all product types.

\section{Objective Functions}

This study takes significant interest in understanding the impact of different product routing on energy, throughput and lead time. Throughput is the number of products that are produced by the production system within a certain period of time. Energy is total amount of electricity consumed by the system during the period under consideration. Lead Time is defined as the average time that the product spends in the shop floor passing through each process step till it gets through the last process. The ultimate goal of the company is to choose the best possible routing for each product type so that the energy is minimised, throughput is maximised and the lead time is minimised. As explained earlier, in Weighted Sum method, each sub-objective is solved as a single-objective problem which then will be scaled and weighted depending on its relative importance.

\section{Energy Minimisation}

As a first scenario, the aforementioned decision variables are configured and fed into OptQuest ${ }^{\circledR}$ with the objective function set on Minimisation of Energy. Optimisation was run with the Energy as the main objective function to be minimised with automat ic stop. As the problem was a determin istic problem, only one replication was performed. Table 5 shows, total run (the total number of observed solutions), the best run (the number of observed solutions before reaching the best solution) and the values of objective function are given.

Table 5. Objective values when minimising total energy consumption

\begin{tabular}{lllll}
\hline Total run & Best run & Throughput (pcs) & Energy (kWh) & Lead Time (Min) \\
\hline 303 & 246 & 6426 & $59421.58^{*}$ & 7222.55 \\
\hline
\end{tabular}


It should be noted that in optimising the single objective (energy consumption), the other two objectives (throughput and lead time) are not priority for OptQuest ${ }^{\circledR}$ to optimise. Observing the recommended variable setting for the optimised energy as illustrated in Table 6, the following trend is seen:

- For almost all products, biscuit pressing machine number 5 was chosen.

- For most products the mixing number 3, moulding number 10 and curing oven number 5 were chosen.

OptQuest ${ }^{\circledR}$ selection of these particular machines can be explained as the following: In mixing process, MX3 is recommended by the optimiser engine for almost all products because it consumes less energy than others on stand- by mode. The same reasoning applies for selection of BP5 as well as MP10 and Curing number 5 which uses gas. It is noted that the chosen machines are in fact rated as low energy consumers among other machines.

Table 6. Optimal product routing for the products when minimising total energy consumption

\begin{tabular}{lllll}
\hline Product\# & Mixing & Biscuiting & Moulding & Curing \\
\hline Product 1 & 3 & 5 & 10 & 5 \\
Product 2 & 1 & 5 & 10 & 5 \\
Product 3 & 3 & 5 & 10 & 5 \\
Product 4 & 1 & 5 & 10 & 1 \\
Product 5 & 3 & 5 & 10 & 5 \\
Product 6 & 3 & 3 & 10 & 5 \\
Product 7 & 3 & 5 & 10 & 2 \\
Product 8 & 3 & 5 & 10 & 5 \\
Product 9 & 3 & 5 & 8 & 5 \\
Product 10 & 3 & 5 & 10 & 5 \\
\hline
\end{tabular}

\section{Throughput Maximisation}

As a second scenario, the objective function on OptQuest ${ }^{\circledR}$ is set on maximisation of throughput. OptQuest ${ }^{\circledR}$ was run with automatic stop. The result of optimised throughput shows that OptQuest ${ }^{\circledR}$ arrived to the optimum 15041 (pcs) after 389 total runs as shown in Table 7.

Table 7. Objective values when maximising throughput

\begin{tabular}{lllll}
\hline Total run & Best run & Throughput (pcs) & Energy (kWh) & Lead Time (Min) \\
\hline 389 & 378 & $15041^{*}$ & 69151.49 & 5808.88 \\
\hline
\end{tabular}

From the solution space (decision variable) point of view, the recommended machines under each process are different to the Energy optimisation problem as illustrated in Table 8. Here due to objective function being Throughput Maximisation, the OptQuest ${ }^{\circledR}$ search algorithm is trying to achieve the highest possible product yield by means of job sharing and maximum utilisation.

It is of no surprise to see for each process step, almost all of the machines are utilised. Contrary to the recommended machines of Energy optimisation exercise, this time OptQuest ${ }^{\circledR}$ strategy to maximise throughput is by distributing the products to as many machines as possible.

Table 8. Optimal product routing for the selected products when maximising throughput

\begin{tabular}{lllll}
\hline Product\# & Mixing & Biscuiting & Moulding & Curing \\
\hline Product 1 & 2 & 2 & 9 & 1 \\
Product 2 & 3 & 5 & 10 & 1 \\
Product 3 & 2 & 4 & 5 & 1 \\
Product 4 & 1 & 4 & 5 & 2 \\
Product 5 & 3 & 3 & 4 & 1 \\
\hline
\end{tabular}




\begin{tabular}{lllll}
\hline Product 6 & 2 & 2 & 6 & 2 \\
Product 7 & 2 & 4 & 3 & 3 \\
Product 8 & 2 & 4 & 6 & 4 \\
Product 9 & 1 & 3 & 7 & 5 \\
Product 10 & 1 & 2 & 8 & 5 \\
\hline
\end{tabular}

\section{Lead Time Minimisation}

As a final scenario, the minimisation of the lead time is the third single objective problem to solve by OptQuest ${ }^{\circledR}$. Similar to the previous optimisation, the OptQuest ${ }^{\circledR}$ will stop when it finds the optimum point based on its built in algorithm. After 361 runs as shown in Table 9, it arrives at the Lead Time with the value of 4780.51 minutes as the best possible result.

Table 9. Objective values when maximising throughput

\begin{tabular}{lllll}
\hline Total run & Best run & Throughput (pcs) & Energy (kWh) & Lead Time (Min) \\
\hline 361 & 359 & 10364 & 67454.11 & $4780.51^{*}$ \\
\hline
\end{tabular}

As for the decision variable( as in Table 10), it is noticed that the OptQuest ${ }^{\circledR}$ algorithm uses the same search strategy as it did for minimising lead time and proposes job sharing and line balancing to other machines.

Table 10. Optimal product routing for the selected products when maximising throughput

\begin{tabular}{lllll}
\hline Product \# & Mixing & Biscuiting & Moulding & Curing \\
\hline Product 1 & 2 & 5 & 9 & 3 \\
Product 2 & 3 & 2 & 10 & 3 \\
Product 3 & 2 & 2 & 2 & 2 \\
Product 4 & 1 & 2 & 10 & 3 \\
Product 5 & 2 & 4 & 5 & 1 \\
Product 6 & 3 & 2 & 8 & 5 \\
Product 7 & 3 & 4 & 6 & 1 \\
Product 8 & 1 & 1 & 4 & 2 \\
Product 9 & 2 & 3 & 3 & 4 \\
Product 10 & 2 & 1 & 9 & 4 \\
\hline
\end{tabular}

\section{Multi-objective Minimisation}

To solve the problem of optimisation of three objectives simultaneously, all three objectives need to be combined to one objective which then similarly can be solved within OptQuest ${ }^{\circledR}$ simulation-optimisation platform. As discussed earlier, the proposed optimisation engine utilised the weighted sum method to combine several objective functions. Table 11 shows the best and worst values of each objective function generated from the single optimisation problems solved above. For the ease of the reader to locate the optimum results of each objective, the * sign is placed next to the optimum values.

Table 11. The best and the worst of each objective during single optimisation runs

\begin{tabular}{lllll}
\hline Primary objective function & $\begin{array}{l}\text { Throughput } \\
\text { (pcs) }\end{array}$ & $\begin{array}{l}\text { Energy } \\
\text { (kWh) }\end{array}$ & $\begin{array}{l}\text { Lead time } \\
\text { (min) }\end{array}$ \\
\hline \multirow{2}{*}{ Throughput } & Min & 3,710 & 59,600 & 4,571 \\
\hdashline & Max & $15,041^{*}$ & 70,417 & 8,185 \\
\hline \multirow{2}{*}{ Energy } & Min & 3,710 & $59,422^{*}$ & 5,250 \\
\hdashline & Max & 12,884 & 69,564 & 8,130 \\
\hline \multirow{2}{*}{ Lead time } & Min & 3,710 & 59,600 & $4,781^{*}$ \\
\hline
\end{tabular}




\begin{tabular}{llll}
\hline Min & 3,710 & $59,422^{*}$ & $4,571^{*}$ \\
Max & $15,041^{*}$ & 70,457 & 8,185 \\
\hline
\end{tabular}

The $\min / \max$ values for each objective functions are fed into the OptQuest ${ }^{\circledR}$ as well as the single objective function $f(x)$ which is combination of all three single objectives (see Equation 1 ). The weighted sum method, the optimisation engine also needs the relative importance of each objective function or weights. Since achieving optimum results for all of the objectives at the same time is the main goal of the company, each of the weights (w1, w2 and w3) is set at equal weighing (e.g. 1/3 of total importance which means 0.33). After setting the OptQuest ${ }^{\circledR}$ with the new objective function and weights for each objective, OptQuest ${ }^{\circledR}$ started its search and eventually stopped at 321st run. Table 12 summarises the results for each objective for when the optimum was reached. The OptQuest ${ }^{\circledR}$ result suggests, the optimum energy to produce the highest possible number of products (13450 pcs) is $65265 \mathrm{kWh}$ within 4897 unit of optimum time.

Table 12. Optimal value of objectives with equal importance

\begin{tabular}{lllll}
\hline Total run & Best run & Throughput (pcs) & Energy (kWh) & Lead Time (Min) \\
\hline 321 & 319 & 13450 & 65265 & 4897 \\
\hline
\end{tabular}

For understanding whether the optimised results are actually any better, a baseline scenario is simulated with the current system setting for the whole production system. The duration of the simulation was also for two weeks with the first week discarded as a warm up period.

In order to demonstrate the variation between two sets of three dimensional results, the results on energy and lead time are plotted separately against throughput as in two dimensional graphs. Figure 6 presents the variation between the optimum result and the baseline scenario on energy versus throughput. As it shows the optimal solution led to 4515 pcs in throughput and 5\% decrease in total energy consumed by the system. There is a significant 51\% improvement on the throughput. In Figure 7, the throughput results are plotted against the lead time results. The minimum lead time of 4897 minutes has been improved about 15\% from the baseline lead time.

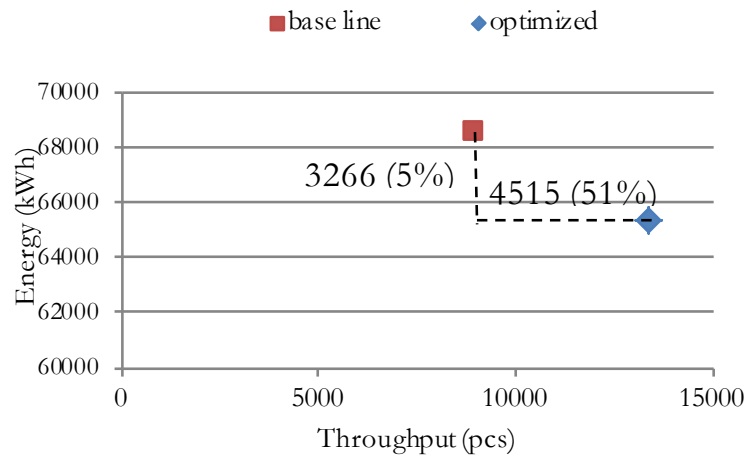

Figure 6. Throughput vs. Energy for baseline and optimal solution

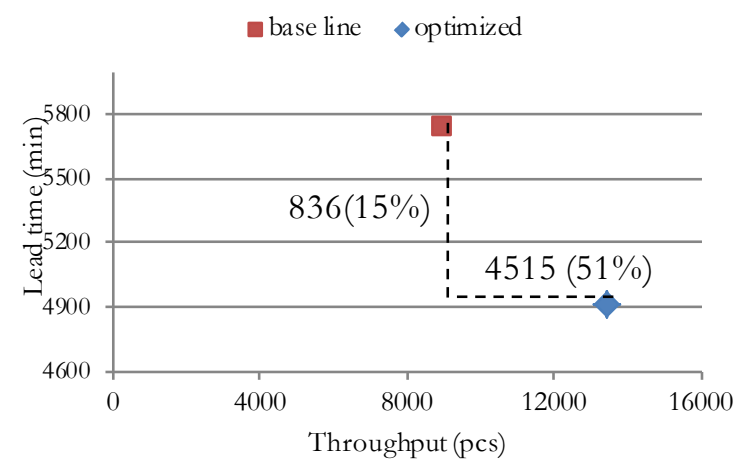

Figure 7. Throughput vs. Lead time for baseline and optimal solution

To explain the significant improvement on throughput and lead time and the reduced energy, the solution space (optimal product routing) is studied. Table 13 presents the OptQuest ${ }^{\circledR}$ choice of optimum routing for each product. Comparing this setting (multi optimisation) and the energy minimisation problem (single optimisation), the choice of machines, in particular moulding machines are much more diverse. Obviously utilising variety of available machines result in lead-time reduction and increase in throughput but adversely affects the energy consumption.

Table 13. Optimal product routing for the selected products

\begin{tabular}{lllll}
\hline Product \# & Mixing & Biscuiting & Moulding & Curing \\
\hline Product 1 & 1 & 4 & 10 & 2 \\
\hline
\end{tabular}




\begin{tabular}{lllll}
\hline Product 2 & 3 & 1 & 10 & 3 \\
Product 3 & 2 & 1 & 9 & 2 \\
Product 4 & 2 & 4 & 10 & 2 \\
Product 5 & 2 & 5 & 6 & 2 \\
Product 6 & 1 & 2 & 8 & 1 \\
Product 7 & 2 & 4 & 1 & 2 \\
Product 8 & 1 & 3 & 2 & 4 \\
Product 9 & 2 & 4 & 1 & 5 \\
Product 10 & 2 & 5 & 5 & 5 \\
\hline
\end{tabular}

\subsection{Sensitivity Analysis}

Sensitivity analysis is a natural step of robust optimisation that follows a systematic approach to changing the value of model decision variables over some range of interest in order to observe how the changes affect model behaviour (Balci, 1998). It also can identify those input variables which the values of objective functions are very sensitive.

Ultimately, the validity of the model can be enhanced by assuring that those values are determined with sufficient accuracy. In this section, how sensitive the value of the objective functions were to the weight of the objective functions was investigated by defining 19 more scenarios in addition to the three single objective scenarios. For each scenario, a different combination of weights is selected for the objectives; see Table 14. The sensitivity of the objective weights was analysed by comparing 22 scenarios with a different combination of weights. The values for each objective vary according to weight change and show they are sensitive to changing weights. For example, when scenario S9 is compared with S0 (a 40\% reduction in the throughput weight) the throughput objective was reduced by around 8.3\% (from 15041 pcs in S0 to 14115 pcs in S9) whereas in a non-sensitive model, more reduction was expected (around $40 \%$ reduction in throughput).

Table 14. Optimisation results for 21 scenarios

\begin{tabular}{|c|c|c|c|c|c|c|c|}
\hline Scenario & $\begin{array}{l}\text { Throughput } \\
\text { weight }\end{array}$ & $\begin{array}{l}\text { Energy } \\
\text { weight }\end{array}$ & $\begin{array}{l}\text { Lead } \\
\text { weight }\end{array}$ & Time & $\begin{array}{l}\text { Throughput } \\
\text { (pcs) }\end{array}$ & $\begin{array}{l}\text { Energy } \\
\text { (kWh) }\end{array}$ & $\begin{array}{l}\text { Lead } \\
\text { time(min) }\end{array}$ \\
\hline $\mathrm{BS}$ & & & & & 8935 & 68530.8 & 5733.3 \\
\hline S0 & 1 & 0 & 0 & & 15041 & 69151.5 & 5808.8 \\
\hline $\mathrm{S} 1$ & 0 & 1 & 0 & & 6426 & 59421.6 & 7222.5 \\
\hline $\mathrm{S} 2$ & 0 & 0 & 1 & & 10364 & 67454.1 & 4780.5 \\
\hline S3 & 0.33 & 0.33 & 0.33 & & 13450 & 65264.7 & 4896.6 \\
\hline $\mathrm{S} 4$ & 0.2 & 0.2 & 0.6 & & 12797 & 67458.8 & 4211.4 \\
\hline S5 & 0.2 & 0.4 & 0.4 & & 11238 & 63466.4 & 4545.8 \\
\hline S6 & 0.2 & 0.6 & 0.2 & & 7465 & 60070.8 & 6362.3 \\
\hline S7 & 0.4 & 0.2 & 0.4 & & 13922 & 66408.5 & 5434.4 \\
\hline S8 & 0.4 & 0.4 & 0.2 & & 11926 & 62589.9 & 5175.6 \\
\hline S9 & 0.6 & 0.2 & 0.2 & & 14115 & 65732.6 & 4936.5 \\
\hline $\mathrm{S} 10$ & 0 & 0.2 & 0.8 & & 12620 & 65332.7 & 4128.7 \\
\hline S11 & 0 & 0.4 & 0.6 & & 9570 & 62949.5 & 4782.7 \\
\hline S12 & 0 & 0.6 & 0.4 & & 7111 & 59943.6 & 6378.0 \\
\hline $\mathrm{S} 13$ & 0 & 0.8 & 0.2 & & 5568 & 59827.7 & 5745.7 \\
\hline S14 & 0.2 & 0 & 0.8 & & 12220 & 66152.4 & 5128.4 \\
\hline S15 & 0.2 & 0.8 & 0 & & 6690 & 59737.8 & 7262.4 \\
\hline S16 & 0.4 & 0 & 0.6 & & 11359 & 69018.0 & 4757.7 \\
\hline S17 & 0.4 & 0.6 & 0 & & 10932 & 60768.9 & 6175.0 \\
\hline S18 & 0.6 & 0 & 0.4 & & 14652 & 68355.5 & 4533.8 \\
\hline S19 & 0.6 & 0.4 & 0 & & 14250 & 62666.1 & 6252.6 \\
\hline S20 & 0.8 & 0 & 0.2 & & 14981 & 66465.3 & 5232.7 \\
\hline S21 & 0.8 & 0.2 & 0 & & 14882 & 65222.4 & 7113.2 \\
\hline
\end{tabular}

Further comparison is performed where the value of objective functions in each scenario was compared with the baseline (i.e. scenario SB). Table 15 summarises the values of objective functions for each scenario as well as the 
absolute and relative deviation between the baseline and other scenarios. The scenarios can be compared with each other to quantify the impact each weight combination has on the objectives.

As explained before, in solving this multi-objective problem, all objectives are important to decision maker; the equal share of 0.33 for each objective signifies scenario 3 (S3) of the presented table. However, it is always possible that the given priority on operation objectives would change according to different business strategies. This highlights the applicability of the sensitivity analysis in understanding the impact that each priority setting (weights) will have on the objectives. It is already expressed earlier that the equal weights of 0.33 , S3 achieved desirable result and could optimise each of the objectives (throughput, energy and lead-time) by 51\%, 5\% and 15\% accordingly.

Table 15. Absolut and relative deviation between baseline and other scenarios

\begin{tabular}{lllllll}
\hline Scenario & Absolute deviation & \multicolumn{5}{c}{ Relative deviation } \\
\hline & Throughput & Energy & Lead time & Throughput & Energy & Lead time \\
\hline S0 & 6106 & 620.7 & 75.5 & $68 \%$ & $1 \%$ & $1 \%$ \\
S1 & -2509 & -9109.2 & 1489.2 & $-28 \%$ & $-13 \%$ & $26 \%$ \\
S2 & 1429 & -1076.7 & -952.8 & $16 \%$ & $-2 \%$ & $-17 \%$ \\
S3 & 4515 & -3266.1 & -836.7 & $51 \%$ & $-5 \%$ & $-15 \%$ \\
S4 & 3862 & -1072 & -1521.9 & $43 \%$ & $-2 \%$ & $-27 \%$ \\
S5 & 2303 & -5064.4 & -1187.5 & $26 \%$ & $-7 \%$ & $-21 \%$ \\
S6 & -1470 & -8460 & 629 & $-16 \%$ & $-12 \%$ & $11 \%$ \\
S7 & 4987 & -2122.3 & -298.9 & $56 \%$ & $-3 \%$ & $-5 \%$ \\
S8 & 2991 & -5940.9 & -557.7 & $33 \%$ & $-9 \%$ & $-10 \%$ \\
S9 & 5180 & -2798.2 & -796.8 & $58 \%$ & $-4 \%$ & $-14 \%$ \\
S10 & 3685 & -3198.1 & -1604.6 & $41 \%$ & $-5 \%$ & $-28 \%$ \\
S11 & 635 & -5581.3 & -950.6 & $7 \%$ & $-8 \%$ & $-17 \%$ \\
S12 & -1824 & -8587.2 & 644.7 & $-20 \%$ & $-13 \%$ & $11 \%$ \\
S13 & -3367 & -8703.1 & 12.4 & $-38 \%$ & $-13 \%$ & $0 \%$ \\
S14 & 3285 & -2378.4 & -604.9 & $37 \%$ & $-3 \%$ & $-11 \%$ \\
S15 & -2245 & -8793 & 1529.1 & $-25 \%$ & $-13 \%$ & $27 \%$ \\
S16 & 2424 & 487.2 & -975.6 & $27 \%$ & $1 \%$ & $-17 \%$ \\
S17 & 1997 & -7761.9 & 441.7 & $22 \%$ & $-11 \%$ & $8 \%$ \\
S18 & 5717 & -175.3 & -1199.5 & $64 \%$ & $0 \%$ & $-21 \%$ \\
S19 & 5315 & -5864.7 & 519.3 & $59 \%$ & $-9 \%$ & $9 \%$ \\
S20 & 6046 & -2065.5 & -500.6 & $68 \%$ & $-3 \%$ & $-9 \%$ \\
S21 & 5947 & -3308.4 & 1379.9 & $67 \%$ & $-5 \%$ & $24 \%$ \\
\hline
\end{tabular}

\section{Conclusion and Outlook}

Most of efficiency improvement decisions are multi-objective problems in which management needs to handle the challenges of conflicting objectives. Due to complexities and uncertainties exist in real-world problems, and a simulation-optimisation was considered as the most practical platform.

There are many examples in literature for solving scheduling problems on a single machine or parallel-machine for minimising for instance tardiness or maximising machine utilisation. However instances that apply multi-objective optimisation, considering energy and traditional business objectives are rarely found within the research field. This paper exploits the use of simulation-optimisation framework for energy efficient production planning and control.

The proposed framework utilises the simulation model for evaluation of performance of the system under different scenarios. As for optimisation part of the framework, several decision variables are evaluated simultaneously, searching the solution space to find optimal or near optimal solution. As presented, improvement opportunities are evaluated and optimised considering all relevant parameters (machine, process chain, factory and product)

From the system perspective, the inclusion of product view in the optimisation of energy consumption for the whole factory shows a great leap towards holistic system improvement. Through optimal product routing, it is possible to achieve highest possible throughput and lowest possible energy consumption. The proposed optimal 
routing would result in 51\% increase in throughput with energy consumption having an increase of 5\%.

In recognition of the importance of life cycle view on achieving environmental sustainability, the opportunity exists to expand the proposed approach to include and span the entire product life-cycle. Further research should consider modelling and optimisation of other life-cycle phases including product design, material extraction, use and the end-of-life.

\section{Acknowledgments}

The authors would like to acknowledge Australian Research Council (ARC) and our industrial partners for funding this research project.

\section{References}

Abdulmalek, F. A., \& Rajgopal, J. (2007). Analyzing the benefits of lean manufacturing and value stream mapping via simulation: A process sector case study. International Journal of Production Economics, 107(1), 223-236. https://doi.org/10.1016/j.ijpe.2006.09.009

Alvandi, S., Bienert, G., Li, W., \& Kara, S. (2015). Hierarchical Modelling of Complex Material and Energy Flow in Manufacturing Systems. Procedia CIRP, 29, 92-97. http://dx.doi.org/10.1016/j.procir.2015.01.023

Alvandi, S., Li, W., Schönemann, M., Kara, S., \& Herrmann, C. (2016). Economic and environmental value stream map (E2VSM) simulation for multi-product manufacturing systems. International Journal of Sustainable Engineering, 1-9. http://dx.doi.org/10.1080/19397038.2016.1161095

Balci, O. (1998). Verification, Validation, and Testing. In J. Banks (Ed.), Handbook of Simulation (pp. 335-393) Hoboken, NJ: John Wiley \& Sons, Inc. https://doi.org/10.1002/9780470172445.ch10

Banks, J. (1998). Handbook of Simulation; Principles, Methodology, Advances, Applications, and Practice. Hoboken, NJ: John Wiely \& Sons. https://doi.org/10.1002/9780470172445

Banks, J., Carson, J. S., Nelson, B. L., \& Nicol, D. M. (2010). Discrete-Event System Simulation (Fifth ed.): Upper Saddle River, NJ: Prentice Hall.

Bianchi, L., Dorigo, M., Gambardella, L. M., \& Gutjahr, W. J. (2009). A survey on metaheuristics for stochastic combinatorial optimization. Natural Computing: an international journal, 8(2), $239-287$. https://doi.org/10.1007/s11047-008-9098-4

Calabrese, J. M., \& Hausman, W. H. (1991). Simultaneous Determination of Lot Sizes and Routing Mix in Job Shops. Management Science, 37(8), 1043-1057. https://doi.org/10.1287/mnsc.37.8.1043

Dahmus, J. B., \& Gutowski, T. (2004). An environmental analysis of machining. Paper presented at the ASME international mechanical engineering congress and RD\&D expo. https://doi.org/10.1115/IMECE2004-62600

Deb, K. (2001). Multi-Objective Optimization using Evolutionary Algorithms. Hoboken, NJ: John Wiley \& Sons, Inc.

Duggan, K. J. (2012). Creating Mixed Model Value Streams: Practical Lean Techniques for Building to Demand. Boca Raton, FL: CRC Press

Eskandari, H., Mahmoodi, E., Fallah, H., \& Geiger, C. D. (2011). Performance analysis of commercial simulation-based optimization packages: OptQuest and Witness Optimizer. Proceedings of the Winter Simulation Conference, Phoenix, Arizona. https://doi.org/10.1109/WSC.2011.6147946

Fang, K., Uhan, N., Zhao, F., \& Sutherland, J. W. (2011). A new approach to scheduling in manufacturing for power consumption and carbon footprint reduction. Journal of Manufacturing Systems, 30(4), $234-240$. https://doi.org/10.1016/j.jmsy.2011.08.004

Fu, H. P., \& Su, C. T. (2000). A comparison of search techniques for minimizing assembly time in printed wiring assembly. International Journal of Production Economics, 63(1), 83-98. https://doi.org/10.1016/S0925-5273(99)00004-3

Fu, M. C. (2002). Optimization for simulation: Theory vs. practice. INFORMS Journal on Computing, 14(3), 192-215. https://doi.org/10.1287/ijoc.14.3.192.113

Ghadimi, P., Kara, S. and Korn feld, B., 2014, June. Reactive modelling of on-site energy system components for real-time application. In Intelligent Energy and Power Systems (IEPS), 2014 IEEE International Conference on (pp. 219-224). IEEE. https://doi.org/10.1109/IEPS.2014.6874183

Glover, F., Kelly, J. P., \& Laguna, M. (1996). New advances and applications of combining simulation and 
optimization. Proceedings of the 28th conference on Winter simulation, Coronado, California, USA. http://delivery.acm.org/10.1145/260000/256595/p144-glover.pdf?ip=129.94.236.213\&id=256595\&acc=ACTIVE \%20SERVICE\& key=65D80644F295BC0D\%2EB811333C2AA88C82\%2E4D4702B0C3E38B35\%2E4D4702B 0C3E38B35\&CFID $=585292245 \&$ CFTOKEN $=83667118 \& \quad$ acm $\quad=1456291521$ 99bdacda5410305850ddd601 2e52609e

Glover, F., Kelly, J. P., \& Laguna, M. (1999). New advances for wedding optimization and simulation. In Simulation Conference Proceedings, 1999 Winter. https://doi.org/10.1109/WSC.1999.823081

Herrmann, C., Schmidt, C., Kurle, D., Blume, S., \& Thiede, S. (2014). Sustainability in manufacturing and factories of the future. International Journal of Precision Engineering and Manufacturing-Green Technology, 1(4), 283-292. https://doi.org/10.1007/s40684-014-0034-z

Herrmann, C., Thiede, S., Kara, S., \& Hesselbach, J. (2011). Energy oriented simulation of manufacturing systems - Concept and application. CIRP Annals - Manufacturing Technology, 60(1), 45-48. https://doi.org/10.1016/j.cirp.2011.03.127

Jafferali, M., Ven kateshwaran, J., \& Son, Y. J. (2005). Performance comparison of search-based simulation optimisation algorithms for operations scheduling. International Journal of Simulation and Process Modelling, 1(1-2), 58-71. https://doi.org/10.1504/IJSPM.2005.007114

Kelton, W. D., \& Law, A. M. (2000). Simulation modeling and analysis. New York: McGraw Hill.

Kleijnen, J. P. C., \& Wan, J. (2007). Optimisation of simulated systems: OptQuest and alternatives. Simulation Modelling Practice and Theory, 15(3), 354-362. https://doi.org/10.1016/j.simpat.2006.11.001

Marler, R. T., \& Arora , J. S. (2004). Survey of multi-objective optimization methods for engineering. Structural and Multidisciplinary Optimization, 26(6), 369-395. https://doi.org/10.1007/s00158-003-0368-6

McDonald, T., Van Aken, E. M., \& Rentes, A. F. (2002). Utilising Simu lation to Enhance Value Stream Mapping: A Manufacturing Case Application. International Journal of Logistics Research and Applications, 5(2), $213-232$. https://doi.org/10.1080/13675560210148696

Melouk, S. H., Freeman, N. K., Miller, D., \& Dunning, M. (2013). Simulation optimization-based decision support tool for steel manufacturing. International Journal of Production Economics, 141(1), $269-276$. https://doi.org/10.1016/j.ijpe.2012.08.001

Mousavi, S., Kara, S., \& Kornfeld, B. (2014). Energy Efficiency of Compressed Air Systems. Procedia CIRP, 15, 313-318. https://doi.org/10.1016/j.procir.2014.06.026

Mousavi, S., Thiede, S., Li, W., Kara, S., \& Herrmann, C. (2015). An Integrated Approach for Improving Energy Efficiency of Manufacturing Process Chain. International Journal of Sustainable Engineering, 9(1), 11-24 https://doi.org/10.1080/19397038.2014.1001470

Mouzon, G., \& Yild irim, M. B. (2008). A framework to minimise total energy consumption and total tardiness on a single machine. International Journal of Sustainable Engineering, 1(2), $105-116$. https://doi.org/10.1080/19397030802257236

Mouzon, G., Yildirim, M. B., \& Twomey, J. (2007). Operational methods for minimization of energy consumption of manufacturing equipment. International Journal of Production Research, 45(18-19), 4247-4271. https://doi.org/10.1080/00207540701450013

OptTek Systems, I. (2015). http://www.opttek.com/partners.

Rogers, P. (2002, 8-11 Dec. 2002). Optimum-seeking simulation in the design and control of manufacturing systems: experience with OptQuest for Arena. Simulation Conference, 2002. Proceedings of the Winter (Vol. 2, 1142-1150). https://doi.org/10.1109/WSC.2002.1166371

Wang, J., Li, J., \& Huang, N. (2009). Optimal Scheduling to Achieve Energy Reduction in Automotive Paint Shops. Proceedings of the ASME 2009 International Manufacturing Science and Engineering Conference (MSEC2009), 161-167. http://dx.doi.org/10.1115/MSEC2009-84339

\section{Copyrights}

Copyright for this article is retained by the author(s), with first publication rights granted to the journal.

This is an open-access article distributed under the terms and conditions of the Creative Commons Attribution license (http://creativecommons.org/licenses/by/4.0/) 